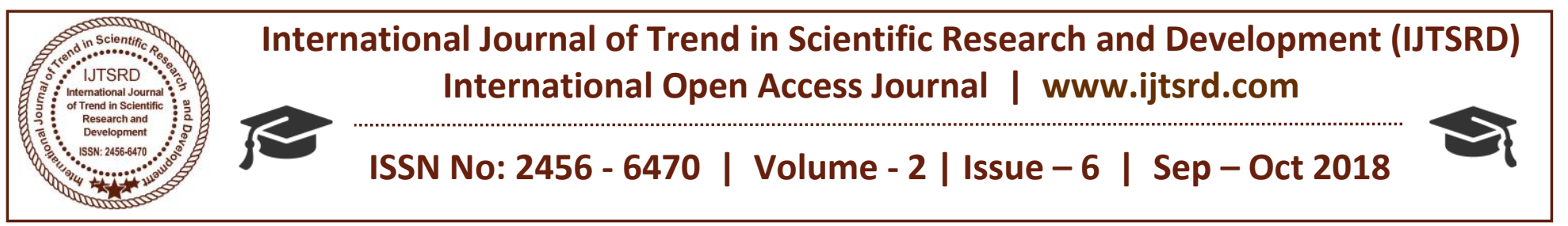

\title{
Development of Hybrid Fibrous Panel for Controlling Acoustics in Home Theatre /Conference Hall
}

\author{
A. Muralikrishnan \\ Lecturer, Department of Textile Technology, \\ P.A.C. Ramasamyraja Polytechnic College, Rajapalayam, Tamil Nadu, India
}

\section{ABSTRACT}

Human ear will acknowledge as sound when frequency is in the range of 20 to $20000 \mathrm{~Hz}$ and more sensitive in the range of $500-4000 \mathrm{~Hz}$. Heat and sound insulation panels are generally composed of nonwoven porous synthetic materials such as rock wool, glass wool, polyurethane, polyester and etc. Though these materials have excellent acoustic properties at high frequencies, their structural properties are not enough to defend against low frequency noise. Multi-purpose concert halls face a dilemma and they host classical music concerts, rock concerts and spoken word performances in a matter of a short period. These different performance types require significantly different acoustic conditions in order to provide the best sound quality to both the performers and the audience. Micro perforated panel absorber backed by air gap is also used in auditoriums and effective only in absorbing specified range of frequencies (low frequency). Hence, it is clear that one type of acoustical absorbers is unable to attenuate wide spectrum of frequency noise. Increased usage of synthetic sound absorption materials leads to higher $\mathrm{CO} 2$ emission and other environmental issues. Therefore, many researches turned towards the production of insulating materials by using natural and bio based materials. Natural materials are becoming a valid alternative to synthetic materials and composite panel is proposed with coir fibre alone which is organic in nature, have excellent insulation against thermal and sound and more resistant to fungi/rot. The present work has been focused on the sound absorption performance nonwoven porous coir matt mounted with and with-out air gap, perforated panel faced porous coir matt with and with-out air gap and perforated panel mounted with air gap.
Keyword: Air gap, coir fibre, insulation, micro perforated panel, natural fibre, nonwoven, porous absorber, sound absorption

\begin{tabular}{|c|c|}
\hline & \\
\hline MPP & Micro perforated panel \\
\hline $\mathrm{d} \odot \mathrm{O}$ & Diameter of perforation, in $\mathrm{mm}$ \\
\hline $\mathrm{b}_{\mathrm{n}}$ & $\begin{array}{l}\text { Hole separation, center to center on the } \\
\text { perforated panel, in } \mathrm{mm}\end{array}$ \\
\hline$t$ & Thickness of panel, in $\mathrm{mm}$ \\
\hline $\mathrm{D}$ OU & $\begin{array}{l}\text { Thickness of cavity behind the } \\
\text { perforated panel }\end{array}$ \\
\hline p clent & Percentage perforation \\
\hline$f$ and & Frequency in $\mathrm{Hz}$ \\
\hline & Circular frequency \\
\hline $\mathrm{m}$ & $\begin{array}{l}\text { Mass term of the specific acoustic } \\
\text { impedance }\end{array}$ \\
\hline $\mathrm{r}$ & $\begin{array}{l}\text { Resistive term of the specific acoustic } \\
\text { impedance }\end{array}$ \\
\hline $\mathrm{j}$ & Imaginary unit \\
\hline $\mathrm{C}-1$ & Velocity of sound in air \\
\hline$\eta$ & Coefficient of viscosity of air \\
\hline$\rho$ & Density of air \\
\hline$\alpha$ & Absorption coefficient \\
\hline$\alpha_{\max }$ & Maximum sound absorption coefficient \\
\hline$\gamma_{a} \& \gamma_{f}$ & $\begin{array}{l}\text { Complex wave propagation constant of } \\
\text { air and porous material }\end{array}$ \\
\hline$z_{a} \& z_{f}$ & $\begin{array}{l}\text { Characteristic impedance of air and } \\
\text { porous material }\end{array}$ \\
\hline$\tau_{a} \& \tau_{f}$ & $\begin{array}{l}\text { Surface acoustic impedance of air and } \\
\text { porous material }\end{array}$ \\
\hline$\sigma$ & Flow resistivity of porous material \\
\hline
\end{tabular}




\section{INTRODUCTION}

The word acoustic is form a Greek word which means hearing and science of sound and is about the production, dissemination, transmission and control of sound. Sound can produce feelings of pleasure and displeasure. The sound which is undesirable is called noise. A noise does not exist unless there is a dissenting observer. Noise may consist of a single pure tone or many tones at different frequencies and intensities. Annoyances caused by noise are stress, feeling of fear, sleep disturbances and speech interferences. Nevertheless, the rapidly growing social conscience of people and the increase of machine noise in general have combined to give great drive towards the study and control of noise. Hence, the noise isolation in buildings is necessary. The sources of noise and vibration are recognizable and can be controlled by using absorbents. When sound wave impinges any materials, the sound energy may be reflected, refracted, transmitted and absorbed. All materials have some sound absorbing properties. A sound reflector forms a solid, impermeable barrier and prevents sound transmission. Human ear will acknowledge as sound when frequency is in the range of 20 to $20000 \mathrm{~Hz}$ but more sensitive in the frequency range of 500 to $4000 \mathrm{~Hz}$.

Nonwoven fiber webs can be considered as noise control elements for a wide range of applications, such as acoustic ceilings and barriers, carpets, and wall claddings. A nonwoven is composed of air and fibre phases that react differently with the sound wave. Even though those materials have excellent acoustic properties at high frequencies, their structural properties are not enough to defend against low frequency noise expect for their possible harm to human health [1]. However, resonance absorbing materials have high absorption coefficients at low and medium frequencies. It is clear that a sound absorber including only one type of acoustical absorbing material is unable to attenuate wide-frequency noise. The commercial efficient sound absorbents are available only in porous structures in the form of fibre felts, foams and composites and are based on petrochemicals such as rock wool, glass wool, polyester and polyurethane [2]. Increased usage of synthetic sound absorption materials leads to higher $\mathrm{CO}_{2}$ emission and other environmental issues. Building's $\mathrm{CO}_{2}$ emissions have been steadily increasing since 1990 and heating and air conditioning account for almost two thirds of building energy consumption. Therefore, many researches turned towards the production of insulating materials by using natural and bio based materials.

Natural fibres have many advantages compare to synthetic fibres, for example low cost, recyclable, biodegradable and huge availability often as a waste product [2,3]. Natural materials are becoming a valid alternative to synthetic materials for making sound absorption panels at a reduced cost and have good thermal insulation properties, have no harmful effects on health and environment. Diameter of natural fibers tends to be larger than synthetic fibers, and also natural fibers have more irregular shapes in cross section and transverse dimensions. These properties make more interest in making sound absorption material with natural fibres. Various studies proposed the sound absorbent materials from cotton, jute, bamboo, kenaf, kapok, flax, ramie, wood, hemp, coconut, cork, cane, cardboard, sisal and sheep wool fibres.

Coir is a natural organic fibre which is the seed-hair fibre obtained from the outer shell (endocarp) or husk of coconut.al Coconut fiber has excellent characteristics of thermal insulation and sound absorption. In building panels, the coconut fiber is often mixed with binders to improve the characteristics of rigidity, anti-fungus, and flammability. According to official website of International Year for Natural Fibres 2009, approximately, 500000 tonnes of coconut fibres are produced annually worldwide, mainly in India and Srilanka. Its total value is estimated at $\$ 100$ million. India and Srilanka are also the main exporters, followed by Thailand, Vietnam and Indonesia. Around half of the coconut fibres produced is exported in the form of raw fibre. This shows that the coir fibre have potential to be used as raw material for making sound insulation panels.

Fouladi et al. studied a coir-based samples produced using fresh coconut husk with or without the addition of a binder and concluded that the raw coconut fiber resulted in a good sound absorption coefficient at both low and medium frequencies, although in thicker layers, the behaviour was much more remarkable [4]. Mohd et al (2010) analysed the effect of different factors of coir fibre in sound absorption and results showed that increasing coir fiber layer thickness increases the absorption and moves absorption peak towards low frequency for both cases [5]. Increasing the thickness of material enhanced the sound 
absorption in lower frequencies having same average absorption coefficient. Also in another study, Mohd et al analysed the effect of compression on the acoustic performance of single layer coir panel and observed that higher compression rate corresponds to the strong acoustic absorption which is greater than the uncompressed coir fiber. Studies were conducted to measure transmission loss index and acoustic absorption coefficient and made a comparison between them by using natural organic fiber perforated panels with or without filler. The result from experimental works and simulation of multilayer coir fiber showed good absorption coefficient in reducing noise in all spaces.

Multi-purpose concert halls face a dilemma and they host classical music concerts, rock concerts and spoken word performances in a matter of a short period. These different performance types require significantly different acoustic conditions in order to provide the best sound quality to both the performers and the audience [6]. A recommended reverberation time for classical music may be in the range of $1.5-2$ seconds, rock music sounds around 0.8-1.5 seconds for empty halls. Modern rhythmic music often contains high levels of sound energy in the low frequency bands but still requires a high definition for good sound quality. Therefore, in recent years, multilayer acoustic absorbers have been developed and composed of perforated plates, airspaces and porous materials to absorb broadband noise. However, the acoustic absorption of these multi-layer acoustic absorbers is mainly dependent on their fabrication. Zulkifi et al (2008) experimented the performance of coir fibre with perforated panel facing and results showed that coir fibre with perforated panel have higher sound absorption for the low frequencies [7]. Increasing the sound absorption at low frequency can be a great contribution to noise control engineering. Air gap or perforated facing is usually used to enhance the absorption at low frequency. Ayub et al. (2009) developed a panel composed of coir fibre layer in different thickness $20 \mathrm{~mm}, 35 \mathrm{~mm}$ and $50 \mathrm{~mm}$ with air gap backed by rigid wall was used to analyze the acoustic absorption performance of coir fibre and found that addition of air gap moves the absorption towards low frequencies [8]. Zulkifli et al (2010) Studied the performance of sound absorber consisted perforated plate with porous coir backing and found that porous layer backing can improve noise absorption coefficient at low and high frequencies with significant increasing [9]. The aim of present work is to develop fibrous composite panel from nonwoven porous coir matt and micro perforated panels for sound insulation for home theatres/conference hall. The samples are assembled to various configurations like nonwoven porous coir matt mounted with and with-out air gap, perforated panel faced porous coir matt with and with-out air gap and perforated panel mounted with air gap [10].

\section{THEORY}

Sound propagation in Micro Perforated Panels Maa's Theory

The MPP absorbers have a simple structure and absorption characteristics that are exactly predictable. The panel may be made of any material from cardboard, plastic, plywood to sheet metal, with any finishing or decoration to suit the purpose. In a perforated panel, the energy dissipation of a sound wave into heat is produced by viscous thermal losses inside the perforations. As the air molecules travels through the perforations, friction losses occur. This effect can be enhanced by reducing the diameter of the perforation to the submillimeter size. An MPP placed in front of a rigid wall acts as a resonator. The air volume between the panels and the wall plays the role of /spring. It is compared to a Helmholtz resonator that can be tuned to provide a maximum of absorption in a determined resonance frequency. The approximated and exact theory of an MPP was first proposed by Maa in 1975 and 1998 respectively [1113]. The single layer of MPP mounted at distance D from a rigid wall is assumed to equivalent electroacoustical circuit as shown in Figure 1b. The sound wave impinging on the structure is equivalent to a source of sound pressure $2 p$ as produced on the rigid wall with the time factor exp $(-j \omega t)$ suppressed throughout (analogous to the open-circuit voltage) and internal resistance $\rho c$ as that of air with $\rho$ the air density and $\mathrm{c}$ the sound speed. The equivalent circuit of a single layer of MPP mounted at distance D from a rigid wall, where $\mathrm{r}$ and $\omega m$ are the specific acoustic resistance and reactance of the perforations [14-15].

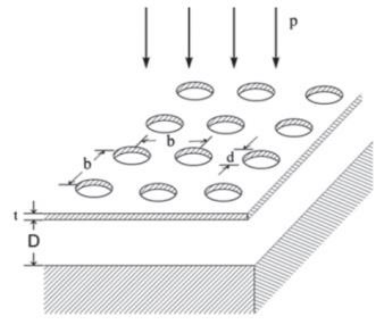

(a)

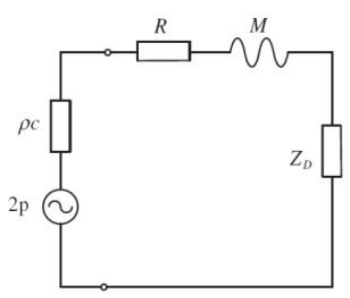

(b)
Figure1. Schematic diagrams of MPP absorber and its equivalent circuit 
According to Maa's theory, the specific impedance of a MPP is equal to the specific acoustic impedance of a single tube (plus end corrections) divided by the perforation ratio (total area of the perforation on a unit area of panel), thus the specific acoustic impedance of MPP normalized by $\rho c$ (the characteristic impedance of air) can be calculated by

$$
z_{M P P}=\frac{Z_{1}}{p \rho c}=r+j \omega m
$$

With

$$
\begin{gathered}
r=\frac{32 \eta t}{p \rho c} \frac{t}{d^{2}}\left\{\sqrt{1+\frac{k^{2}}{32}}+\frac{\sqrt{2 k}}{8} \frac{d}{t}\right\} \\
\omega m=\frac{\omega t}{p c}\left\{1+\frac{1}{\sqrt{3^{2}}+\frac{k^{2}}{32}}+0.85 \frac{d}{t}\right\}
\end{gathered}
$$

Where $k$ is the perforation constant, $k=d \sqrt{\omega \rho / 4 \eta}$ and $p$ is the perforation ratio, $p=78.5 d^{2} / b^{2}$ if the holes are arranged in squares separated by spacing $(b \mathrm{~mm})$ [16]. The normal specific acoustic impedance of air

$$
Z_{D}=-j \cot (\omega D / c)
$$

Based on the equivalent circuit, the normalised specific acoustic impedance of the entire structure can be calculated by

$$
z=r+j \omega m-j \cot (\omega D / c)
$$
cavity behind the MPP, again normalized by $\rho c$ :

most midrange and high frequencies), the absorption coefficient of the material (typically related to the density of the materials) and the angle of incidence for the sound wave. There are two stages in travelling of sound wave: $1^{\text {st }}$ Stage- from the speaker to wall through the absorptive layer and $2^{\text {nd }}$ Stage- pass back from wall to ear through the absorptive layer [9]. During the travel, the sound wave gets attenuated and loss its energy. The attenuation is due to transmission of sound wave through the panel and transitions into a different medium. There is an impedance mismatch in various stages i.e. between the air and the panel, the panel and the air behind the panel, the air and the wall, the wall and the air behind the panel, the air behind the panel and the panel again between the panel and the listen in room. This impedance mismatch causes the original sound wave to lose additional energy.

Many models are available for predicting the sound absorption mechanisms in the pores of porous materials and are generally distinguished based on distinctive absorption mechanism and the type of pores. Delany and Bazley found to be a simple model for predicting acoustic behaviour of fibrous porous absorbing thaterials only employing the nonacoustical characteristics of air flow resistivity. According to their model, complex wave propagation constant $\gamma_{f}$ and characteristic impedance $Z_{f}$ of porous material depend mainly on the angular frequency $\omega$ and on the flow resistivity $\sigma$. A good fit of the measured values of $\gamma_{f}$ and $Z_{f}$ has been obtained with the following expressions:

$$
\gamma_{f}=\frac{2 \pi f}{c}\left\{1+0.0978 X^{-0.7}-j 0.189 X^{-0.595}\right\}
$$

For normal incidence of sound wave, the absorption coefficient derived by

$$
\alpha=\frac{4 r}{(1+r)^{2}+\left(\omega m-\cot (\omega D / c)^{2}\right.}
$$

$$
\begin{gathered}
Z_{f}=\rho c\left\{1+0.057 X^{-0.754}-j\left(0.087 X^{-0.732}\right)\right\} \\
X=\frac{\rho f}{\sigma}
\end{gathered}
$$

The maximum absorption coefficient is

$$
\alpha \max =\frac{4 r}{(1+r)^{2}}
$$

\section{Sound propagation in Porous Material}

As the sound wave from the speaker travels through the absorbing material on its way to the wall, its magnitude is reduced. The amount of reduction is related to a number of factors such as the frequency of the sound, the thick of the material (4 inches of absorptive material is typically sufficient to absorb
Where, $\rho$ is the air density, $\mathrm{C}$ is the sound speed in the air, $f$ is the frequency of the sound wave, $L_{f}$ is the thickness of porous layer.

Delany and Bazley suggest the following boundary for the validity of their laws in terms of boundaries of b, as follows: $0.01<X<1$. It may not be expected that single relations provides a perfect prediction of acoustic behaviour of all the porous materials in the frequency range defined in the above equation. 
If the porous material is backed with a rigid wall, the surface acoustic impedance of the porous material can be expressed as

$$
\Gamma_{f}=Z_{f} \cot h \cot h\left(\gamma_{f} L_{f}\right)
$$

\section{Sound propagation in air}

The complex wave propagation constant $\gamma_{a}$ and characteristic impedance $Z_{a}$ of air can be expressed as,

$$
\begin{gathered}
\gamma_{a}=j k_{a}=j \frac{2 \pi f}{c} \\
Z_{a}=\rho c
\end{gathered}
$$

If the air gap is backed with a rigid wall, the surface acoustic impedance of the air gap can be expressed as

$$
\Gamma_{a}=Z_{a} \cot h \cot h\left(\gamma_{a} L_{a}\right)
$$

Where, $L_{a}$ is the thickness of air space, $\mathrm{k}_{\mathrm{a}}$ is the wave number of air.

\section{MATERIALS}

Micro perforated panels (MPP)

The panel may be made of any material from cardboard, plastic, plywood to sheet metal, with any finishing or decoration to suit the purpose. Wooden/plywood panels are selected as it is a natural material and environmentally friendly. These panels can be easily processed into perforated panel and installed as indoor acoustical panels. Plywood of $3.4 \mathrm{~mm}$ thickness was purchased from local market with density of $67.27 \mathrm{~kg} / \mathrm{m}^{3}$ and perforations were made using a hand drill. Considering the sound frequency to be absorbed and drill configurations, the perforation diameter and hole spacing were optimized to $0.6 \mathrm{~mm}$ and $4 \mathrm{~mm}$ respectively. The physical properties of micro perforated panels used in this work are summarized in Table 1.

Table1. Physical properties of micro perforated panels

\begin{tabular}{|c|c|c|c|c|c|}
\hline $\begin{array}{c}\text { Sampl } \\
\mathbf{e}\end{array}$ & $\begin{array}{c}\text { Material } \\
\text { type }\end{array}$ & $\begin{array}{c}\text { Thic } \\
\mathbf{n e s s} \\
(\mathrm{mm})\end{array}$ & $\begin{array}{c}\text { Hole } \\
\mathbf{d i a} \\
(\mathbf{m m}) \\
\text { MPP1 }\end{array}$ & $\begin{array}{c}\text { Hole } \\
\text { spacin } \\
\mathbf{g} \\
(\mathbf{m m})\end{array}$ & $\begin{array}{c}\text { Ope } \\
\mathbf{n} \\
\text { area } \\
(\%)\end{array}$ \\
\hline Plywood & 3.4 & 0.6 & 4 & 1.76 \\
\hline $\begin{array}{c}\text { Plywood } \\
\text { with } \\
\text { nonwove } \\
\text { n backing }\end{array}$ & 3.6 & 0.6 & 4 & 1.76 \\
\hline MPP3 & Plywood & 3.4 & 2 & 12 & 2.18 \\
\hline MPP4 & Plywood & 6 & 2 & 12 & 2.18 \\
\hline
\end{tabular}

\section{Porous coir matt samples}

Coconut fibre is extracted from the outer shell of a coconut. The common name, scientific name and plant family of coconut fibre is Coir, Cocos nucifera and Arecaceae (palm) respectively. The coconut fibres have excellent sound absorption characteristics and thermal insulation. White or green coir fibres may be extracted from green coconuts and brown fibres may be extracted from fully matured coconuts. The brown coir fibres were collected from Pollachi, Tamil nadu and dried using drying chamber. The dried coir fibre is then processed in hackler machine in two stages for effective fibre opening, removing husk and dust from fibres. The opened fibres are then passed to needle punching machine where the fibres are made to entangle and formed as a sheet. Figure 2 shows the various images about coconut plant. In order to get the structural integration, $22 \%$ of the natural rubber latex was sprayed over the coir matt and cured. Finally, the porous coir matt was prepared in 3 different thickness of $15 \mathrm{~mm}, 20 \mathrm{~mm}$ and $30 \mathrm{~mm}$ and their densities are $110 \mathrm{~kg} / \mathrm{m}^{3}, 110 \mathrm{~kg} / \mathrm{m}^{3}$ and 90 $\mathrm{kg} / \mathrm{m}^{3}$ respectively.

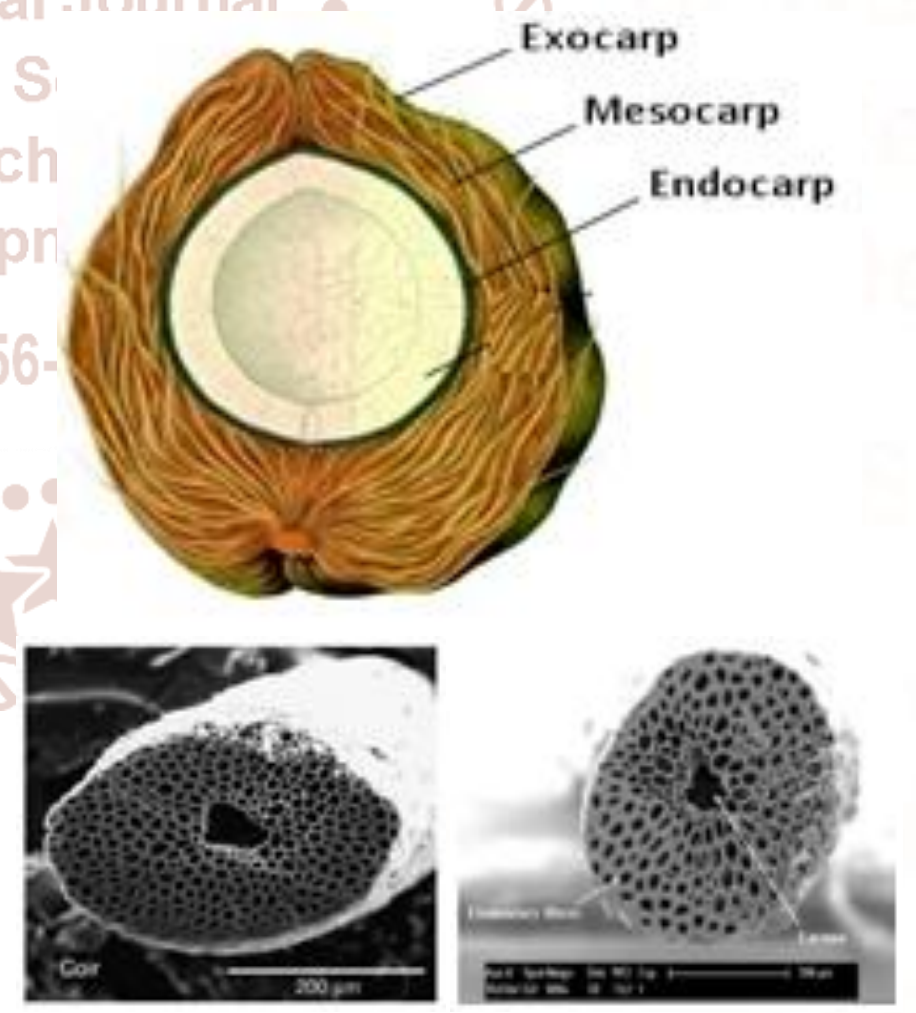

Figure2. Various stages of coconut plant

The prepared samples were kept in standard testing temperature $\left(20^{\circ} \mathrm{C} \pm 2{ }^{\circ} \mathrm{C}\right)$ and relative humidity $(65 \% \pm 2 \%)$ before testing. The physical properties of nonwoven porous coir matt samples used in this work are summarized in Table 2. 
International Journal of Trend in Scientific Research and Development (IJTSRD) ISSN: 2456-6470

Table2. Physical properties of porous coir matt samples

\begin{tabular}{|c|c|c|c|}
\hline $\begin{array}{c}\text { Sample } \\
\text { ID }\end{array}$ & $\begin{array}{c}\text { Thickness } \\
(\mathbf{m m})\end{array}$ & $\begin{array}{c}\text { Weight } \\
\left(\mathrm{g} / \mathrm{m}^{2}\right)\end{array}$ & $\begin{array}{c}\text { Density } \\
\left(\mathbf{K g} / \mathbf{m}^{3}\right)\end{array}$ \\
\hline C1 & 15 & 1650 & 110 \\
\hline C2 & 15 & 2625 & 175 \\
\hline C3 & 15 & 3150 & 210 \\
\hline C4 & 20 & 2200 & 110 \\
\hline C5 & 25 & 2750 & 110 \\
\hline
\end{tabular}

\section{Nonwoven scrim}

Hydro entangled nonwoven was considered for this work and purchased from commercial market. Hydro entangled nonwoven made from 80/20 Viscose/Polyester fibres with $0.55 \mathrm{~mm}$ thickness, weight of $100 \mathrm{~g} / \mathrm{m}^{2}$ and have flow resistivity of 230 Pa. s/ m.

\section{Experimental procedure}

Figure 3 shows the representation of various configurations of samples followed during measurements. Porous coir matt samples, MPP and air gap are considered for making effective experimental procedure.

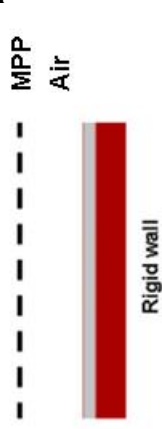

(a)
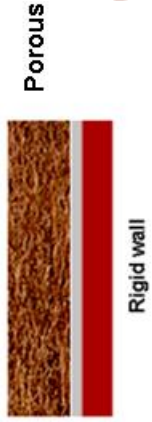

(b)

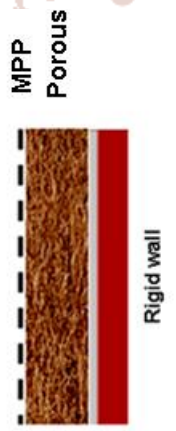

(c)

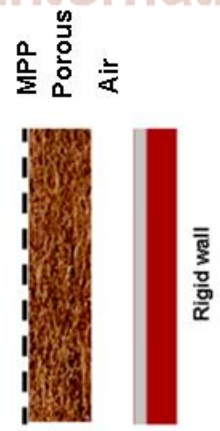

(d)
A. MPP backed by air cavity

B. Porous absorber

C. MPP backed by porous absorber

D. MPP backed by porous and air cavity

Figure3. Representation of various configurations

The details about sample arrangements during measurement are shown in Table 3.

Table3. Sample arrangements during measurement

\begin{tabular}{|l|l|l|}
\hline Sample ID & Specification Air gap ( $\mathrm{mm}$ ) \\
\hline
\end{tabular}

\begin{tabular}{|c|c|c|}
\hline S1 & MPP1 & 50 \\
\hline S2 & MPP2 & 50 \\
\hline S3 & MPP1+C1 & 35 \\
\hline S4 & MPP1+C2 & 35 \\
\hline S5 & MPP1+C3 & 35 \\
\hline S6 & MPP3+C2 & - \\
\hline S7 & MPP4+C2 & - \\
\hline
\end{tabular}

IV. TESTING METHODS

Sound Absorption Coefficient by Impedance Tube Method (ISO 10534-2)

The current focus on noise-control issues and the importance of sound quality, acoustical characterization of product is becoming increasingly relevant to manufacturers/designers. The acoustic characterization of MPP backed by porous coir matt and air gap were tested at PSGTECH'S COEINDUTECH, Coimbatore using impedance tube method. This method is one of the well accepted test method for measuring the sound absorption measurement and the normal incidence sound absorption coefficient was determined using the transfer function method according to standard ISO 10534-2. Figure 4 shows a sketch of the Bruel \&Kjaer Standing Wave Apparatus. Impedance Tube Kit $(50 \mathrm{~Hz}-6.4 \mathrm{kHz})$ Type 4206 consists of: a 100 $\mathrm{mm}$ diameter tube (large tube), a $29 \mathrm{~mm}$ diameter tube (small tube), sample holders (29 and $100 \mathrm{~mm}$ ) and extension tubes (29 and $100 \mathrm{~mm}$ ). A large-tube setup is used to measure parameters in the frequency range from $50 \mathrm{~Hz}$ to $1.6 \mathrm{kHz}$ and small tube setup in the frequency range from $500 \mathrm{~Hz}$ to $6.4 \mathrm{kHz}$.

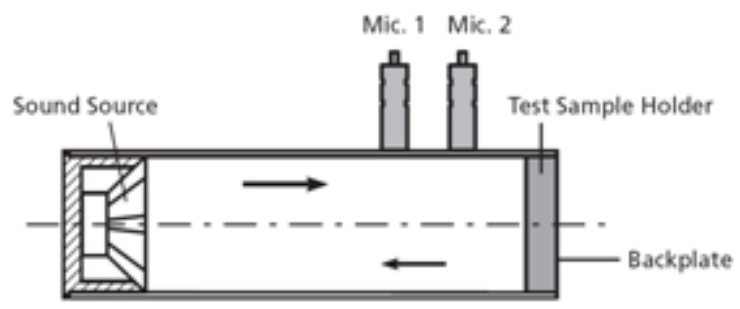

(a) Impedance tube

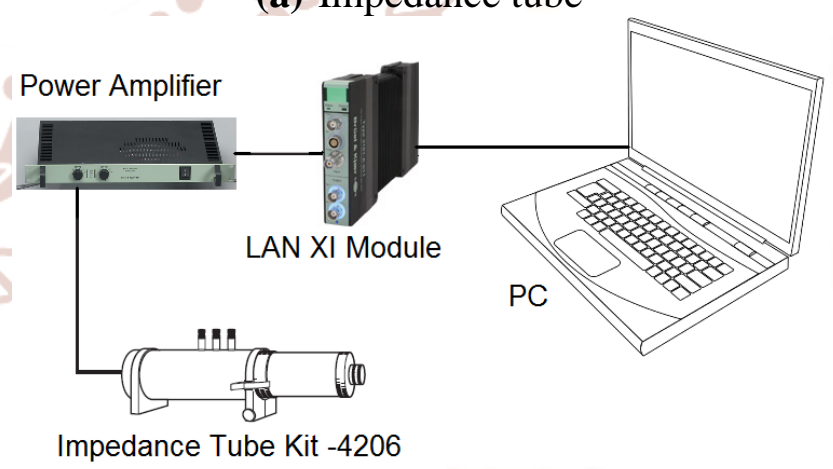

(b) Experimental setup

Figure4. Bruel \& Kjaer standing wave apparatus

A loudspeaker (sound source) located at one end produces an acoustic wave which travels through the pipe and reflects from the test sample located at another end. The phase interference between the incident waves and reflected from the test sample will result in the formation of a standing wave pattern in the pipe. If $100 \%$ of the incident wave is reflected, 
then the incident and reflected waves have the same amplitude; the nodes in the pipe have zero pressure and the antinodes have double the pressure. If some of the incident sound energy is absorbed by the sample, then the incident and reflected waves have different amplitudes; the nodes in the pipe no longer have zero pressure. By measuring the sound pressure at two fixed locations and calculating the complex transfer function using a two-channel digital frequency analyzer, it is possible to determine the sound absorption and complex reflection coefficients and the normal acoustic impedance of the material. In order to get accuracy and repeatability, three set of samples were developed in each configuration and sound absorption coefficient was measured. The average of three measurements in all the configurations has been considered for comparison between the samples.

\section{RESULTS AND DISCUSSION}

Results for micro perforated panel- theoretical against experimental

With the help of Maa's theory, the significant parameters of the MPP absorber such as relative acoustic resistance (r), resonance frequency and perforate constant can be derived theoretically. Figure 5 shows the comparison of theoretical and experimental results of sound absorption characteristics of single leaf MPP. The maximum absorption coefficient and resonance frequency of theoretical and experimental result are $0.98 \& 500 \mathrm{~Hz}$ and $0.97 \& 630 \mathrm{~Hz}$ respectively. In this case, there is no significant difference noticed in maximum absorption coefficient but a lift noticed in the absorption curve of experimental result than theoretical for the frequency range $400-2500 \mathrm{~Hz}$. Also there is an increase in absorption noticed in frequency around $4000 \mathrm{~Hz}$ in experimental result than theoretical. However, the entire trends of sound absorption behaviour of theoretical and experimental results are similar.

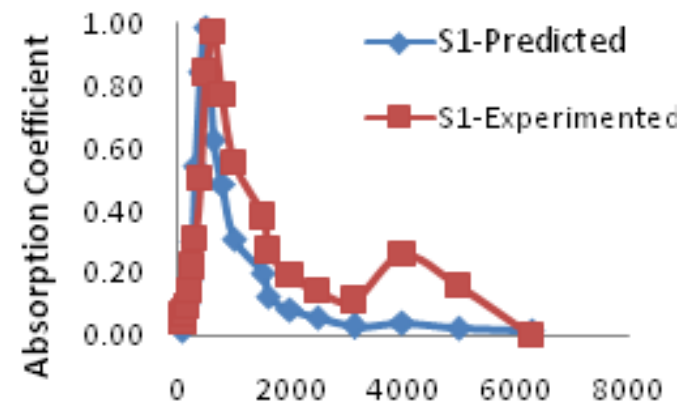

Frequency, $\mathrm{Hz}$

Figure5. Absorption characteristics of single leaf MPP $\mathrm{t}=3.4 \mathrm{~mm}, \mathrm{~d}=0.6 \mathrm{~mm}, \mathrm{~b}=4 \mathrm{~mm}, \mathrm{D}=50 \mathrm{~mm}$.

\section{Effect of nonwoven scrim backing on MPP}

Figure 6 shows the comparison of sound absorption coefficient of single leaf MPP with and without nonwoven scrim backing followed by air gap. The results of sample S1 and S2 are insignificant for the frequency range $63-160 \mathrm{~Hz}$; increase noticed in absorption coefficient of S2 for the frequency range $200-3150 \mathrm{~Hz}$ compared to S1. Also, the maximum absorption and resonance frequency of $\mathrm{S} 2$ are 0.86 and $500 \mathrm{~Hz}$ respectively which is lower than S1 (0.97 and $630 \mathrm{~Hz}$ ). The addition of nonwoven scrim at the back of MPP increases the acoustic resistance of entire system and lead to reduction in maximum absorption coefficient.

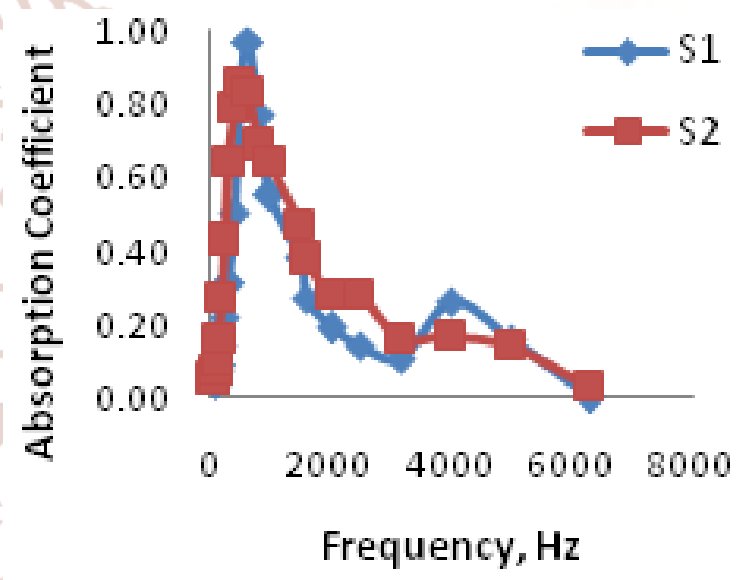

Figure6. Absorption characteristics of single leaf MPP $\mathrm{t}=3.4 \mathrm{~mm}, \mathrm{~d}=0.6 \mathrm{~mm}, \mathrm{~b}=4 \mathrm{~mm}, \mathrm{D}=50 \mathrm{~mm}$.

Results for nonwoven porous coir matt on MPP+ Porous configuration

The absorption of MPP3 backed by $15 \mathrm{~mm}$ air gap has low frequency of range $630-1500 \mathrm{~Hz}$ only. The maximum absorption coefficient 0.49 at $800 \mathrm{~Hz}$ and does not have any absorption at higher frequencies. At the same time, porous coir matt has absorption only at higher frequency range and does not have low frequency absorption. But the MPP backed by porous coir matt sample S6 have absorption at both low and high frequencies. The low frequency absorption trend of S6 is followed based on MPP3 and high frequency trend followed by porous coir matt. Figure 7 shows the absorption behaviour of MPP backed by porous coir matt. The similar trend was also observed in sample S7. Hence, it was proved that when porous nonwoven is faced with MPP enhance the absorption at low frequency range. 


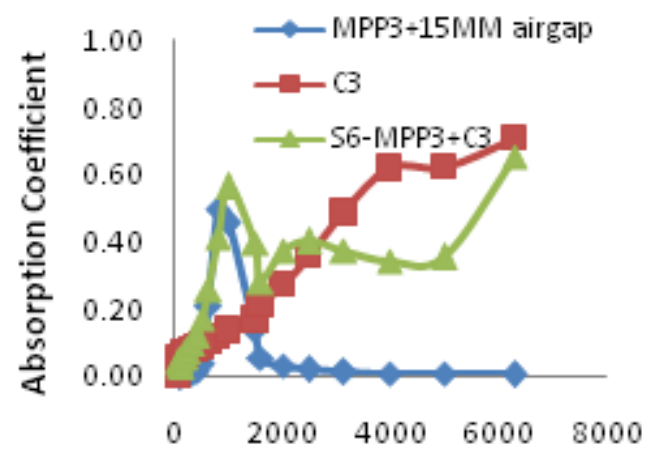

Frequency, $\mathrm{Hz}$

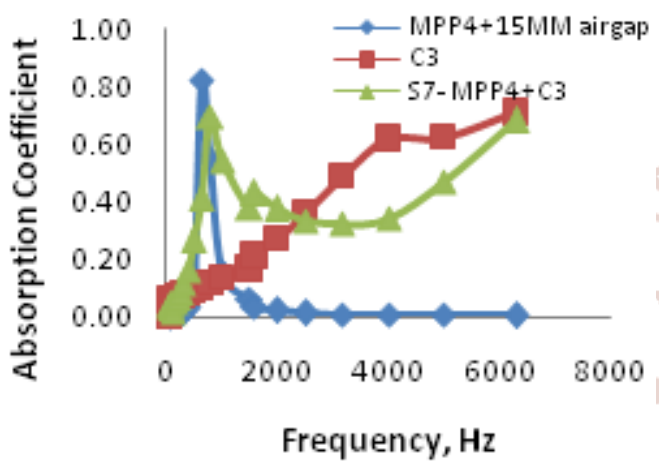

Figure7. Absorption characteristics of MPP backed by porous coir matt

Effect of nonwoven porous coir matt on MPP + Porous + Air gap configuration

The sample $\mathrm{S} 1$ is optimized to have the maximum absorption coefficient 0.97 at $500 \mathrm{~Hz}$ and half absorption bandwidth between 315 and $800 \mathrm{~Hz}$. In general, MPP1 and air gap contributes for good absorption at lower frequency range and porous nonwoven matt contributes for higher frequency range. In order to get wide band absorber, porous layer have to be inserted in between the MPP and air gap. In this section, the effect of porous coir matt in the MPP with air gap configuration is discussed. The absorption coefficient of MPP backed by porous coir matt is slightly lower than that of MPP with air gap for the entire frequency range $63-6300 \mathrm{~Hz}$. In this case, the effect of porous coir matt does not helpful in increase or wider the absorption band as aimed. It should be noted that the acoustic resistance of the MPP with air gap is already optimized to maximum; so inserting porous coir matt in between MPP and air gap provides additional acoustic resistance and makes the total resistance of the system too large [17]. When hole diameter is $0.6 \mathrm{~mm}$, the absorption coefficient becomes lower when a porous coir matt is inserted. In order to get significant effect of porous coir matt on absorption coefficient, compromise is needed in designing MPP with lower acoustic resistance.

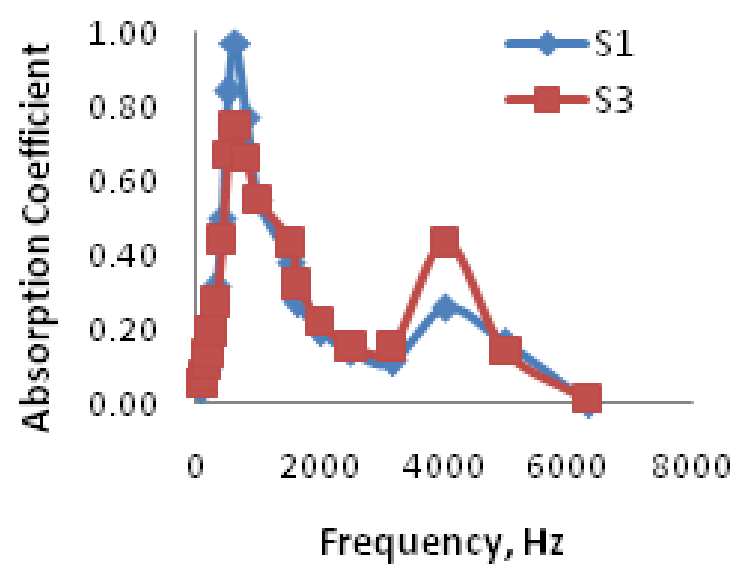

Figure8. Absorption characteristics of MPP backed by air gap and MPP backed by porous matt and air gap

\section{Effect of density of nonwoven coir matt}

In this section, the effect of porous coir matt density for the same thick in MPP backed by porous coir matt and air gap is discussed. The effect of density can be varied without affecting the thick of $15 \mathrm{~mm}$ and absorption characteristics of samples are shown in figure 9. Out of three densities, porous coir matt with density of $110 \mathrm{Kg} / \mathrm{m}^{3}$ have lowest absorption coefficient for the entire frequency range. From the Figure 9, it is clear that when density of porous coir matt increases, the absorption coefficient of MPP backed by porous coir and air gap increases. This may be due to more number of coir fibres present in the porous coir matt with density of $210 \mathrm{Kg} / \mathrm{m}^{3}$. The loss in energy of sound wave is more when more number of fibres presents in the porous layer. But there is no significant difference noticed in the absorption coefficient between the porous coir matt with densities of $175 \mathrm{Kg} / \mathrm{m}^{3}$ and $210 \mathrm{Kg} / \mathrm{m}^{3}$ for the frequency range $63-3150 \mathrm{~Hz}$ and porous coir matt with $210 \mathrm{Kg} / \mathrm{m}^{3}$ have higher absorption peak at 4000 $\mathrm{Hz}$ than others.

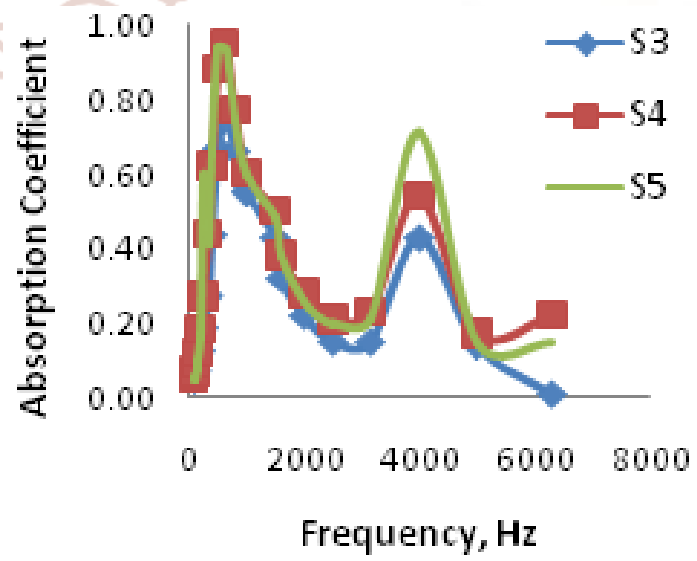

Figure9. Absorption characteristics of different densities of porous matt in MPP backed by porous matt and air gap 


\section{Effect of MPP thickness}

Figure 10 shows the absorption curve of sample S6 and S7. The trends of absorption curve at low frequencies are based on MPP configuration and trend of absorption curve at high frequencies are based on porous coir matt in both the samples. The sample S6 and S7 have maximum absorption coefficient of 0.56 at $1000 \mathrm{~Hz}$ and 0.69 at $800 \mathrm{~Hz}$ respectively. This is due to increase in thickness of sample S7 compared to S6. Hence, increasing thickness of MPP shifts the absorption curve towards low frequencies.

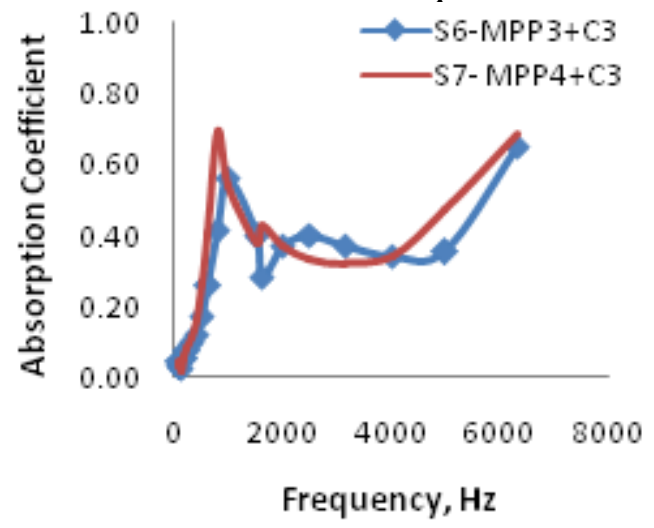

Figure 10. Absorption characteristics of different configuration of MPP backed by porous matt

\section{CONCLUSION}

The prediction of acoustic performance of MPP was much useful in designing the MPP with respect to the end uses. The insertions of porous nonwoven coir matt support the absorption and provide wide band absorption. The sound absorption of MPP backed by porous nonwoven coir matt follow the trend of MPP at low frequency and porous nonwoven matt at higher frequency. If the MPP is optimized to its maximum absorption characteristics, the acoustic of the MPP is higher and addition of porous nonwoven coir matt also adds further resistance to the system. In this case, the sound absorption characteristic of porous nonwoven coir matt is insignificant. In order to get wide band absorber with MPP backed by porous nonwoven coir matt and air gap, the compromise is required in designing the MPP.

\section{REFERENCES}

1. Maria Ernestina Alves Fidelis, Thatiana Vitorino Castro Pereira, Otávio da Fonseca Martins Gomes, Flávio de Andrade Silva and Romildo Dias Toledo Filho," The effect of fiber morphology on the tensile strength of natural fibers", Journal of Materials Research and Technology, DOI: 10.1016/j.jmrt.2013.02.003, Vol. 2, 2013, pp.149157 ,
2. Ghotbi Ravandi, M. R., Mardi H., Langari A.A.A., Mohammadian M. and Khanjani N., "A Review on the Acoustical Properties of Natural and Synthetic Noise Absorbents", Open Access Library Journal, Vol. 2 / 2015, http://dx.doi.org/10.4236/oalib.1101598

3. Hoda Soliman Seddeq, Nermin M Aly, Ali Marwa A. And Elshakankery M.H., "Investigation on Sound Absorption Properties for Recycled Fibrous Materials", Journal of Industrial Textiles, Vol. 43, No.1/2012, pp. 56-73.

4. Mohd Jailani Mohd Nor., Ayub Md., Rozli Zulkifli., Nowshad Amin and Mohammad Hosseini Fouladi, "Effect of Different Factors on the Acoustic Absorption of Coir Fiber", Journal of Applied Sciences, Vol.10 /2010, pp. 2887-2892.

5. Mohd Jailani Mohd Nor., Ayub Md., Rozli Zulkifli., Nowshad Amin and Mohammad Hosseini Fouladi, "Effect of Compression on the Acoustic Absorption of Coir Fibre", American Journal of Applied Sciences, Vol.7, No. 9/2010, pp.1285-1290.

6. Niels Werner Larsen, Eric R. Thompson and Anders C. Gade, "Variable Low Frequency Absorbers for Multipurpose Concert Halls", Viewed on 10 August 2016, <www.flexac.com/wpcontent/uploads/2014/05/ASA2005vari.pdf>

7. Rozli Zulkifli, Zulkarnain and Mohd Jailani Mohd Noor, "Noise Control Using Coconut Coir Fiber Sound Absorber with Porous Layer Backing and Perforated Panel", American Journal of Applied Sciences, Vol. 7, No.2/2010, pp.260-264.

8. Ayub M. D., Mohd Nor M. J., Now shad Amin and Rozli Zulkifi, "A Preliminary Study of Effect of Air Gap on Sound Absorption of Natural Coir Fibre", Proceedings of the regional engineering postgraduate conference, Malaysia, 20 \& 21 October/2009.

9. Zulkifi R., Mohd Nor M. J., Mat Tahir M. F., Ismail A.R. and Nuawi M. Z., "Acoutstic properties of Multi-layer Coir fibres Sound Absorption Panel", Journal of Applied Sciences, Vol. 8, No. 20/2008, pp.3709-3714.

10. Zulkifi R., Mohd Nor M. J., Mat Tahir M. F., Ismail A.R. and Nuawi M.Z., "Acoutstic Properties of Multi-layer Coir fibres Sound Absorption Panel", Journal of Applied Sciences, Vol. 8, No. 20/2008, pp.3709-3714. 
International Journal of Trend in Scientific Research and Development (IJTSRD) ISSN: 2456-6470

11. Maa DY. Theory and design of micro perforated panel sound-absorbing constructions. Sci Sinica $1975 ; 17: 55-71$.

12. Maa DY. Micro perforated-panel wideband absorber. Noise controls Eng J 1987; 29:77-84.

13. Maa DY. Potential of micro perforated panel absorber. J Acoust Soc Am 1998;104:2861-6

14. Rayleigh L. Theory of sound. 2nd Ed. New York: Dover Publications; 1945.

15. Crandall IB. Theory of vibrating systems and sound. New York: Van Notrand; 1926.

16. Heidi Ruiz Villamil, "Acoustic Properties of Micro perforated Panels and Their Optimization by Simulated Annealing”, PhD Thesis, 2012, University Polytechnic of Madrid, Spain.

17. Sakagami K et al, "Sound Absorption Characteristics of A Single Micro perforated Panel Absorber Backed by A Porous Absorbent Layer", Acoustics Australia, Vol.39/No.3, 2011, pp.95100.

18. Val Yachmenev, Ioan Negulescu and Chen Yan., "Thermal Insulation Properties of Cellulosicbased Nonwoven Composites", Journal of Industrial Textiles, Vol. 36, No. 1/2006, pp. 7387.

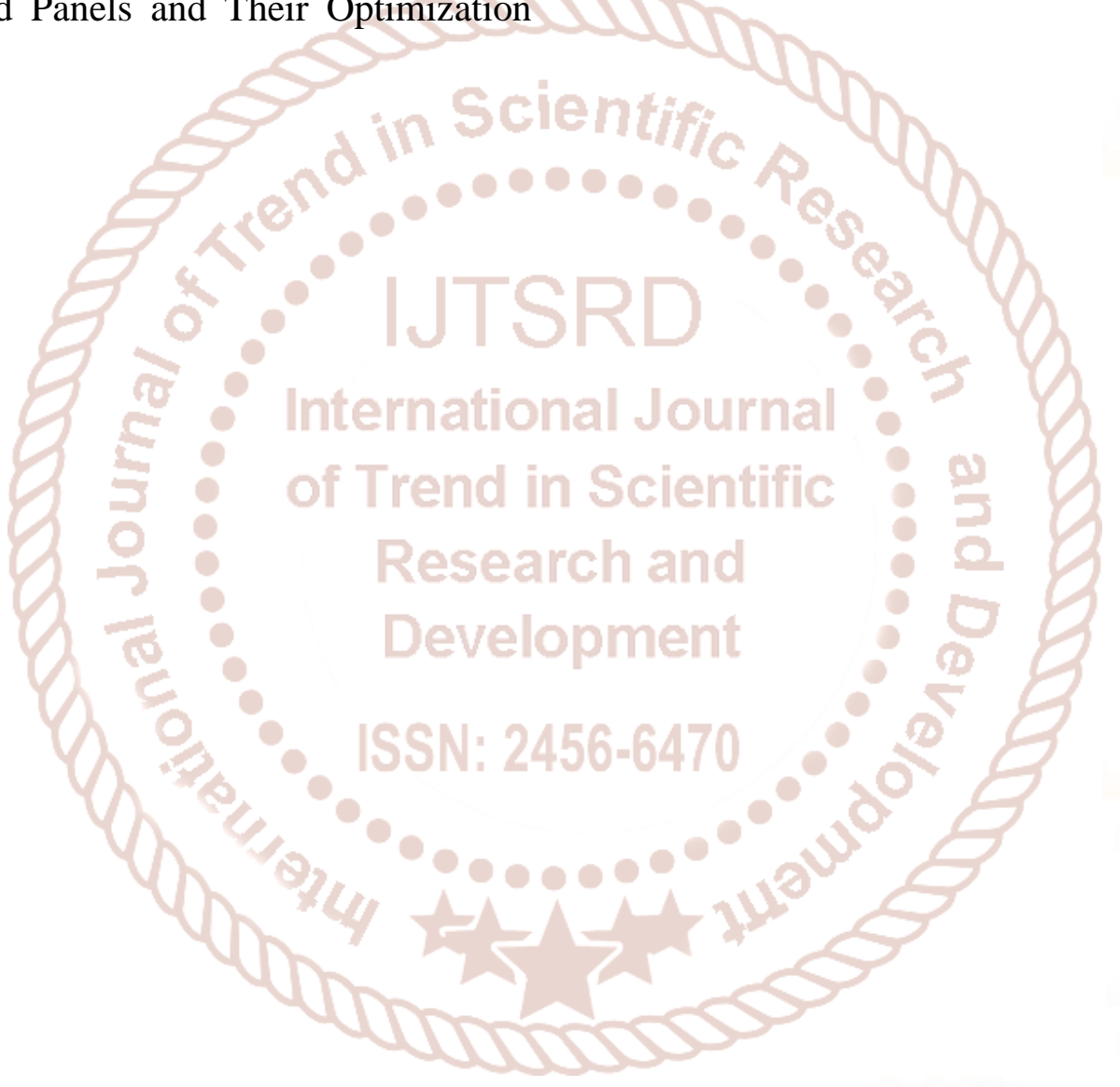

